\title{
Flora polínica da Reserva do Parque Estadual das Fontes do Ipiranga (São Paulo, Brasil) Família: 135-Asclepiadaceae
}

\author{
Cynthia Fernandes Pinto da Luz ${ }^{1,3}$, Fernanda Jacinto Albanese ${ }^{1}$, Angela Maria da Silva Corrêa ${ }^{1}$, Maria Amélia \\ Vitorino da Cruz-Barros ${ }^{1}$ e Maria Isabel Tauil de Moura Guimarães ${ }^{2}$
}

Recebido: 18.09.2008; aceito: 23.04.2009

ABSTRACT - (Pollen flora of "Reserva do Parque Estadual das Fontes do Ipiranga" (São Paulo, Brasil). Family: 135-Asclepiadaceae). Pollinia of nine genera and 16 species of Asclepiadaceae occurring in the "Reserva do Parque Estadual das Fontes do Ipiranga" were examined: Asclepias curassavica L., Blepharodon nitidum (Vell.) J.F. Macbr., Ditassa burchellii var. vestita (Malme) Fontella, Ditassa hispida (Vell.) Fontella, Ditassa tomentosa (Decne.) Fontella, Gomphocarpus physocarpus E. Mey., Gonianthela axillaris (Vell.) Fontella \& E.A. Schwarz, Matelea glaziovii (E. Fourn.) Morillo, Orthosia urceolata E. Fourn., Oxypetalum appendiculatum Mart., Oxypetalum capitatum subsp. capitatum Mart., Oxypetalum insigne (Decne.) Malme, Oxypetalum pachyglossum Decne., Oxypetalum pedicellatum Decne., Oxypetalum wightianum Hook. \& Arn., Tassadia subulata var. subulata (Vell.) Fontella \& E.A. Schwarz. Descriptions, illustrations and observations of all studied taxa and keys for species of Ditassa and Oxypetalum based on pollinia morphology are provided. Key words: Asclepiadaceae, pollinarium, morphology

RESUMO - (Flora polínica da Reserva do Parque Estadual das Fontes do Ipiranga (São Paulo, Brasil). Família: 135-Asclepiadaceae). No presente trabalho, foram estudados os polinários de nove gêneros e 16 espécies de Asclepiadaceae ocorrentes na "Reserva do Parque Estadual das Fontes do Ipiranga: Asclepias curassavica L., Blepharodon nitidum (Vell.) J F. Macbr., Ditassa burchellii var. vestita (Malme) Fontella, Ditassa hispida (Vell.) Fontella, Ditassa tomentosa (Decne.) Fontella, Gomphocarpus physocarpus E. Mey., Gonianthela axillaris (Vell.) Fontella \& E.A. Schwarz, Matelea glaziovii (E. Fourn.) Morillo, Orthosia urceolata E. Fourn., Oxypetalum appendiculatum Mart., Oxypetalum capitatum subsp. capitatum Mart., Oxypetalum insigne (Decne.) Malme, Oxypetalum pachyglossum Decne., Oxypetalum pedicellatum Decne., Oxypetalum wightianum Hook. \& Arn., Tassadia subulata var. subulata (Vell.) Fontella \& E.A. Schwarz. São apresentadas descrições e ilustrações para todas as espécies estudadas, bem como chaves para identificação das espécies dos gêneros Ditassa e Oxypetalum tomando como base a morfologia dos polinários.

Palavras-chave: Asclepiadaceae, polinário, morfologia

\section{Introdução}

O presente trabalho é parte integrante do projeto elaborado por Melhem et al. (1984), que tem como objetivo caracterizar morfologicamente os grãos de pólen e polinários das famílias ocorrentes na Reserva do Parque Estadual das Fontes do Ipiranga (PEFI), além de complementar os levantamentos taxonômicos realizados na mesma área, segundo planejamento apresentado por Melhem et al. (1981) e finalizado em Nakajima et al. (2001). O formato atual da Flora Polínica do PEFI segue Cruz-Barros \& Souza (2005). O estudo morfológico dos polinários é importante como material de referência para a palinologia aplicada servindo como base de dados para pesquisas sobre polinização zoófila.

Atualmente as famílias Asclepiadaceae e Apocynaceae são agrupadas em uma única família, Apocynaceae s.l. (Endress \& Bruyns 2000, Endress \& Stevens 2001), entretanto no presente estudo Asclepiadaceae foi tratada como uma família separada, pois a "Flora Polínica da Reserva do Parque Estadual das Fontes do Ipiranga" segue o sistema de Cronquist (1968), conforme definido no projeto proposto por Melhem et al. (1981).

1. Instituto de Botânica, Caixa Postal 3005, 01061-970 São Paulo, SP, Brasil

2. Universidade Estadual Paulista, Campus de Botucatu, Instituto de Biociências, Departamento de Botânica, Distrito de Rubião Junior s.n., 18618-000 Botucatu, SP, Brasil

3. Autor para correspondência: cyluz@yahoo.com.br 
A família Asclepiadaceae, segundo Pereira (1998) está representada na vegetação do PEFI pelas espécies Asclepias curassavica L., Blepharodon nitidum (Vell.) J.F. Macbr., Ditassa burchellii var. vestita (Malme) Fontella, Ditassa hispida (Vell.) Fontella, Ditassa tomentosa (Decne.) Fontella, Gomphocarpus fruticosus (L.) Ait. f., Gonianthela axillaris (Vell.) Fontella \& E.A. Schwarz, Matelea glaziovii (E. Fourn.) Morillo, Orthosia urceolata E. Fourn., Oxypetalum appendiculatum Mart., Oxypetalum capitatum subsp. angustum Malme, Oxypetalum insigne (Decne.) Malme, Oxypetalum pachyglossum Decne., Oxypetalum pedicellatum Decne., Oxypetalum wightianum Hook. \& Arn. e Tassadia subulata var. subulata (Vell.) Fontella \& E.A. Schwarz. Entretanto, Gomphocarpus fruticosus (L.) Ait. f., segundo Pereira (2005), é sinônimo de Gomphocarpus physocarpus E. Mey., já Oxypetalum capitatum subsp. angustum, segundo Farinaccio (2005), é sinônimo de Oxypetalum capitatum subsp. capitatum.

Verhoeven \& Venter (2001) salientam que nas Apocynaceae s.l., a subfamília Asclepiadoideae se diferencia de Periplocoideae e Secamonoideae por apresentar polínias com grãos de pólen livres e recobertas por uma parede que cobre toda a polínia.

Segundo dados disponíveis na literatura os polinários da família apresentam polínias com variadas formas, desde lanceoladas a globulares, com diversos tipos intermediários. A orientação da polínia em relação a caudícula pode ser pendular, erecta ou horizontal. As caudículas de diferentes espécies podem exceder o tamanho da polínia e do corpúsculo, enquanto que outras são aparentemente sésseis, possuindo ou não asas. As caudículas também variam em forma (filiforme, triangular e "club-shaped") e a inserção na polínia pode ser terminal a subterminal. Os corpúsculos apresentam maior consistência que as polínias, no entanto, o tamanho da polínia pode atingir quatro vezes o do corpúsculo (Ikuse 1956, El-Gazzar \& Hamza 1973, El-Gazzar et al.1974, Melhem et al. 2003, Konno 2005).

\section{Material e métodos}

Flores maduras dos espécimes utilizados foram coletadas do material botânico depositado no Herbário Científico do Estado "Maria Eneyda P. Kauffmann Fidalgo" (SP). Alguns exemplares listados em Pereira (1998) apresentaram polinários insuficientes, optandose por coletas em exsicatas provenientes de outras localidades.

As flores foram colocadas para ferver em água destilada para a reidratação do material. Depois de fervidas, procurou-se retirar intacto o par de polínias de cada flor (isto é, inserido às suas caudículas e ao corpúsculo), com um estilete de ponta bem fina, depositando o conjunto em lâmina de vidro para microscopia.

As medidas foram realizadas em 10 amostras de cada táxon, selecionadas ao acaso, visando uma uniformidade. Para a polínia, mediu-se o comprimento frontal, sua largura frontal no maior eixo, descreveu-se a sua forma e orientação com relação a caudícula e ao corpúsculo. Para a caudícula foram medidos os comprimento frontal, a largura na sua porção mediana, largura na inserção com a polínia, largura na inserção com o corpúsculo, definiu-se a sua forma geral, descreveu-se a sua orientação com relação ao eixo do corpúsculo, assinalando-se a presença ou ausência da membrana reticulada basal e da asa. Para o corpúsculo foram realizadas medidas do comprimento frontal e da sua largura no maior eixo frontal, caracterizando a sua forma. Foi também caracterizada a relação corpúsculo/polínia quanto as suas dimensões no comprimento frontal.

A terminologia adotada para os polinários foi a sugerida por Newton (1984), enquanto que a padronização da descrição geral das estruturas, com suas medidas, foi baseada em El-Gazzar \& Hamza (1973) e El-Gazzar et al. (1974).

As ilustrações dos polinários foram obtidas, em microscopia óptica, fotografados digitalmente no fotomicroscópio OLYMPUS BX 50, acoplado a uma câmera de vídeo e microcomputador (PC) usando-se o programa Pro-Plus, versão 3.0, para Windows.

\section{Resultados e Discussão}

\section{Asclepias L.}

\section{Asclepias curassavica L.}

Figuras 1-3

Polínia: clavada, de inserção terminal e orientação pendular em relação a caudícula.

Caudícula: de orientação sinuosa a sigmóide, plana, retangular, inseridas na região mediana do corpúsculo.

Corpúsculo: ovóide a obovóide.

Relação de comprimento corpúsculo/polínia: corpúsculo menor do que a polínia.

Medidas ( $\mu \mathrm{m})$ : N.A. Rosa \& J.M. Pires 3798: compr. da polínia $=404,0 \pm 1,0$, larg. da polínia $=$ $152,6 \pm 1,0$; compr. da caudícula $=190,1 \pm 0,8$, larg . da caudícula na porção mediana $=47,9 \pm 0,6$, larg. da caudícula na inserção com o corpúsculo $=22,6 \pm 0,4$, 
larg. da caudícula na inserção com a polínia $=22,5$ $\pm 0,5$; compr. do corpúsculo $=175,9 \pm 1,2$, larg. do corpúsculo $=90,1 \pm 0,4$.

M.R.O. Santos et al.26: compr. da polínia $=403,4$ $\pm 0,8$, larg. da polínia $=143,6 \pm 1,5 ;$ compr. da caudícula $=193,0 \pm 1,5$, larg. da caudícula na porção mediana $=37,7 \pm 0,5$, larg. da caudícula na inserção com o corpúsculo $=24,9 \pm 0,5$, larg. da caudícula na inserção com a polínia $=27,6 \pm 0,6$; compr. do corpúsculo $=$ $192,0 \pm 0,9$, larg. do corpúsculo $=92,2 \pm 0,8$.

T. Sendulsky 499: compr. da polínia $=404,3 \pm 0,7$, larg. da polínia $=130,4 \pm 0,7$; compr. da caudícula $=181,7 \pm 1,3$, larg. da caudícula na porção mediana $=40,4 \pm 0,5$, larg. da caudícula na inserção com o corpúsculo $=24,2 \pm 0,5$, larg. da caudícula na inserção com a polínia $=22,9 \pm 0,3$; compr. do corpúsculo $=$ $171,2 \pm 1,5$, larg. do corpúsculo $=86,1 \pm 0,5$.

Observações: Os materiais da Reserva J.A. Correa 18 (SP), G. Eiten \& L. Eiten 2306 (SP), C.G. Fonseca 22 (SP), C.R.F. Guedes et al. 25 (SP), R.P. Lyra 58 (SP), W. Mantovani 28 (SP), A.C. Maruffa et al. 4 (SP) e I.T. Menezes \& F.S. Cavalcante 10 (SP), citados por Pereira (1998), não foram medidos por não apresentarem polinários em número suficiente para a análise ou por estarem frutificados. Na literatura, Ikuse (1956) caracterizou o polinário de Asclepias curassavica possuindo corpúsculos $(280 \times 390 \mu \mathrm{m}$ de compr.) e caudículas (500 $\mu \mathrm{m}$ de compr.) maiores que os do presente estudo. $\mathrm{O}$ autor mencionou para essa espécie uma grande variação na amplitude das polínias (360-1030 um), o que não ocorreu nos três espécimes aqui analisados. Já El-Gazzar \& Hamza (1973) descreveram Asclepias curassavica com orientação pendular da polínia, inserção terminal na caudícula e forma tipo clavada, o que corroborou nossas observações. No entanto, as medidas apresentadas pelos autores para os comprimentos da polínia (1.100 $\mu \mathrm{m})$ e dos corpúsculos $(500 \times 300 \mu \mathrm{m})$ foram bem maiores dos que as apresentadas neste trabalho.

Material estudado: 17-XI-1980, N.A. Rosa \& J.M. Pires 3798 (SP178621); 1-IX-1982, M.R.O. Santos et al.26 (SP197110); 7-XII-1966, T. Sendulsky 499 (SP).

\section{Blepharodon Decne.}

\section{Blepharodon nitidum (Vell.) J.F. Macbr.}

Figuras 4-6

Polínia: ovóide a elipsóide, de inserção sub terminal e orientação pendular em relação a caudícula.
Caudícula: de orientação oblíquo-ascendente, cilíndrica, inserida na região basal do corpúsculo, presença de membrana reticulada basal.

Corpúsculo: ovóide a obovóide.

Relação de comprimento corpúsculo/polínia: corpúsculo maior do que a polínia.

Medidas $(\mu \mathrm{m})$ : compr. da polínia $=174,7 \pm 0,9$, larg. da polínia $=133,6 \pm 2,6$; compr. da caudícula $=$ $69,5 \pm 0,5$, larg. da caudícula na porção mediana $=19,2$ $\pm 0,4$, larg. da caudícula na inserção com o corpúsculo $=18,3 \pm 0,5$, larg. da caudícula na inserção com a polínia $=22,8 \pm 0,5 ;$ compr. do corpúsculo $=197,1 \pm$ 1,0, larg. do corpúsculo $=129,1 \pm 1,1$.

Material estudado: 30-X-1901, A. Hammar s.n. (SP15783).

\section{Ditassa R. Br.}

Polínias ovóides a oblongas, de inserção subterminal e orientação pendular em relação às caudículas, as quais apresentam orientação oblíquoascendente a curva, cilíndricas, inseridas na região basal dos corpúsculos, com ou sem membrana reticulada basal; corpúsculos ovóides a oblongos, menores, tão longos ou maiores que as polínias.

\section{Ditassa burchellii Hook. \& Arn. var. vestita} (Malme) Fontella

Figura 7

Polínia: oblonga, de inserção sub terminal e orientação pendular em relação a caudícula.

Caudícula: de orientação oblíquo-ascendente, ausência de membrana reticulada basal.

Corpúsculo: oblongo.

Relação de comprimento corpúsculo/polínia: corpúsculo tão longo quanto a polínia.

Medidas $(\mu \mathrm{m})$ : compr. da polínia $=150,7 \pm 0,8$, larg. da polínia $=79,0 \pm 0,4 ;$ compr. da caudícula $=$ $57,4 \pm 1,2$, larg. da caudícula na porção mediana $=14,0$ $\pm 0,3$, larg. da caudícula na inserção com o corpúsculo $=19,8 \pm 0,5$, larg. da caudícula na inserção com a polínia $=31,5 \pm 0,8 ;$ compr. do corpúsculo $=151,5 \pm$ 1,0, larg. do corpúsculo $=76,8 \pm 0,8$.

Observação: O mesmo exemplar de Ditassa burchellii var. vestita do PEFI foi estudado por Konno (2005) corroborando os dados aqui apresentados.

Material estudado: 26-II-1932, F.C. Hoehne s.n. (SP28827). 


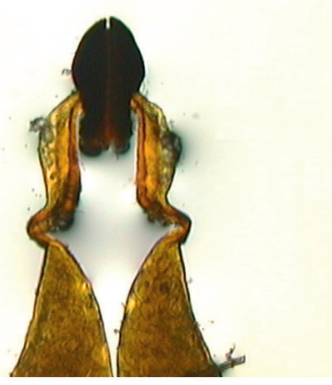

1

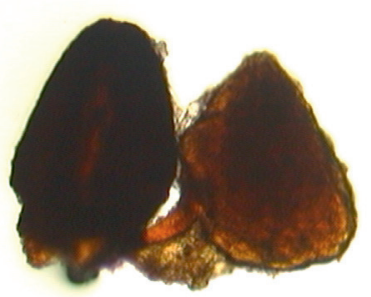

4

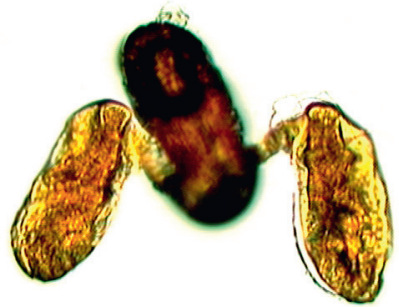

7

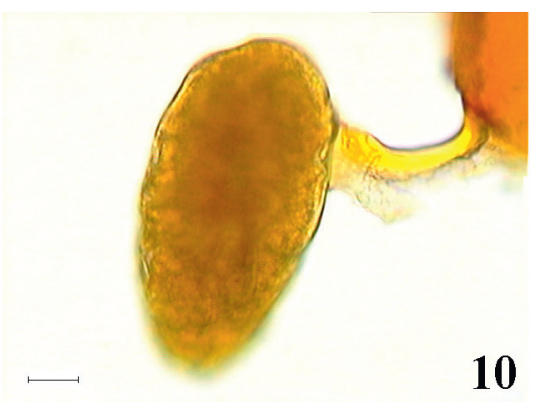

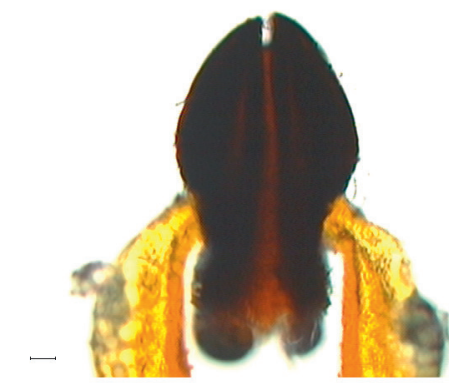

2

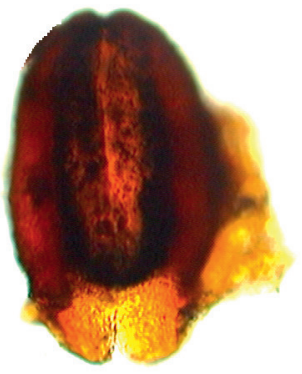

5

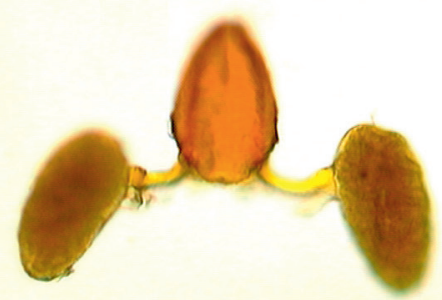

8

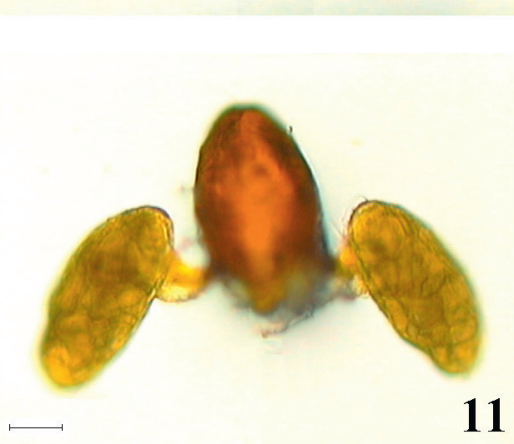

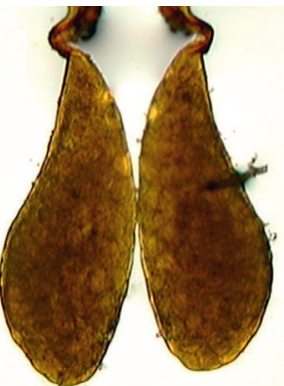

3

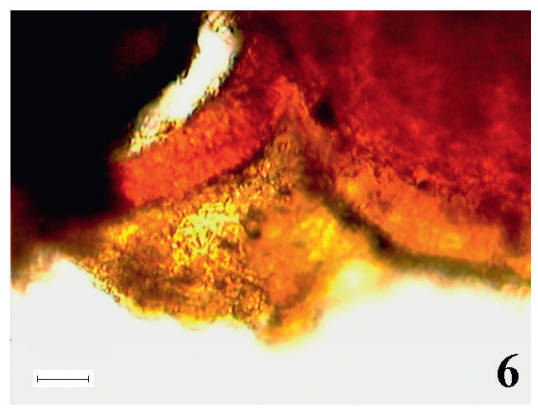

6

Figuras 1-12. Fotomicrografias dos polinários da família Asclepiadaceae. 1-3. Asclepias curassavica L. 1. Vista geral do polinário. 2. Corpúsculo e caudículas. 3. Polínias. 4-6. Blepharodon nitidum (Vell.) Macbr. 4. Vista geral do polinário. 5. Corpúsculo. 6. Caudícula, mostrando a membrana reticulada basal. 7. Ditassa burchellii var. vestita (Malme) Fontella. Vista geral do polinário. 8-10. Ditassa hispida (Vell.) Fontella. 8. Vista geral do polinário. 9. Corpúsculo. 10. Polínia e caudícula. 11-12. Ditassa tomentosa (Decne.) Fontella. 11. Vista geral do polinário. 12. Corpúsculo e caudícula, mostrando a membrana reticulada basal. Escalas nas figuras 1, 3-5, 7, 8, 11, 12 = $50 \mu \mathrm{m}$; demais figuras $=30 \mu \mathrm{m}$.

Figures 1-12. Photomicrographs of pollinaria of Asclepiadaceae. 1-3. Asclepias curassavica L. 1. General view of the pollinarium. 2. Corpuscle and caudicles. 3. Pollinia. 4-6. Blepharodon nitidum (Vell.) Macbr. 4. General view of the pollinarium. 5. Corpuscle. 6. Caudicle, showing the reticulated basal membrane. 7. Ditassa burchellii var. vestita (Malme) Fontella. General view of the pollinarium. 8-10. Ditassa hispida (Vell.) Fontella. 8. General view of the pollinarium. 9. Corpuscle. 10. Pollinium and caudicle. 11-12. Ditassa tomentosa (Decne.) Fontella. 11. General view of the pollinarium. 12. Corpuscle and caudicle, showing the reticulated basal membrane. Scales in the figures $1,3-5,7,8,11,12=50 \mu \mathrm{m}$; remaining figures $=30 \mu \mathrm{m}$. 


\section{Ditassa hispida (Vell.) Fontella}

Figuras 8-10

Polínia: ovóide a oblonga, de inserção sub terminal e orientação pendular em relação a caudícula.

Caudícula: de orientação curva, presença de membrana reticulada basal.

Corpúsculo: ovóide a oblongo.

Relação de comprimento corpúsculo/polínia: corpúsculo menor que a polínia.

Medidas ( $\mu \mathrm{m})$ : G. Davidse \& W.G.D'Arcy 10416: compr. da polínia $=180,2 \pm 1,2$, larg. da polínia $=$ $91,5 \pm 0,7 ;$ compr. da caudícula $=67,9 \pm 2,1$, larg. da caudícula na porção mediana $=13,2 \pm 0,3$, larg. da caudícula na inserção com o corpúsculo $=21,4 \pm 0,6$, larg. da caudícula na inserção com a polínia $=28,8$ $\pm 0,8$, compr. do corpúsculo $=176,7 \pm 1,5$, larg. do corpúsculo $=107,3 \pm 0,6$.

O. Handro s.n., SP74163: compr. da polínia $=$ $217,9 \pm 0,9$, larg. da polínia $=99,3 \pm 0,8$; compr. da caudícula $=64,6 \pm 0,7$, larg. da caudícula na porção mediana $=11,8 \pm 0,3$, larg. da caudícula na inserção com o corpúsculo $=17,8 \pm 0,2$, larg. da caudícula na inserção com a polínia $=37,1 \pm 1,0$; compr. do corpúsculo $=186,3 \pm 1,0$, larg. do corpúsculo $=114,6$ $\pm 0,8$.

F.C. Hoehne s.n., SP32375: compr. da polínia $=$ $190,0 \pm 2,3$, larg. da polínia $=93,9 \pm 1,6$; compr. da caudícula $=61,1 \pm 2,6$, larg. da caudícula na porção mediana $=14,4 \pm 0,3$, larg. da caudícula na inserção com o corpúsculo $=23,7 \pm 0,8$, larg. da caudícula na inserção com a polínia $=33,9 \pm 0,9$; compr. do corpúsculo $=185,4 \pm 1,6$, larg. do corpúsculo $=113,6$ $\pm 0,9$.

M.M.R.F. Melo et al. 66: compr. da polínia $=$ $203,3 \pm 1,0$, larg. da polínia $=95,6 \pm 0,9$; compr. da caudícula $=73,2 \pm 1,8$, larg. da caudícula na porção mediana $=14,1 \pm 0,4$, larg. da caudícula na inserção com o corpúsculo $=17,1 \pm 0,3$, larg. da caudícula na inserção com a polínia $=31,3 \pm 0,7$; compr. do corpúsculo $=199,5 \pm 1,1$, larg. do corpúsculo $=130,5$ $\pm 1,3$.

Observações: Konno (2005) apresentou para Ditassa hispida medidas de comprimento dos corpúsculos dentro da faixa de variação dos quatro espécimes aqui examinados, mas o comprimento apresentado por essa autora para as polínias foi menor, o que gerou diferença com os dados aqui apresentados sobre a relação entre os tamanhos dessas estruturas. As caudículas foram descritas por essa autora como sendo planas e de orientação horizontal enquanto que nos quatro espécimes da Reserva eram cilíndricas e com orientação curva.

Material estudado: 21-II-1976, G. Davidse \& W.G. D’Arcy 10416 (SP); 18-II-1934, O. Handro s.n. (SP74163); 30-I-1935, F.C. Hoehne s.n (SP32375); 27-II-1978, M.M.R.F. Melo et al. 66 (SP).

\section{Ditassa tomentosa (Decne.) Fontella}

Figuras 11-13

Polínia: ovóide a oblonga, de inserção sub terminal e orientação pendular em relação a caudícula.

Caudícula: de orientação curva, presença de membrana reticulada basal.

Corpúsculo: ovóide a oblongo.

Relação de comprimento corpúsculo/polínia: corpúsculo menor ou maior que a polínia.

Medidas ( $\mu \mathrm{m})$ : L.B. Noffs 50 \& M. Goes 501: compr. da polínia $=188,0 \pm 0,8$, larg. da polínia $=$ $90,2 \pm 0,5 ;$ compr. da caudícula $=58,2 \pm 1,4$, larg. da caudícula na porção mediana $=18,6 \pm 0,2$, larg. da caudícula na inserção com o corpúsculo $=26,0 \pm 0,8$, larg. da caudícula na inserção com a polínia $=38,2$ \pm 0 ,6; compr. do corpúsculo $=195,2 \pm 1,3$, larg. do corpúsculo $=109,1 \pm 0,6$.

J.S. Silva 289: compr. da polínia $=204,0 \pm 1,6$, larg. da polínia $=97,6 \pm 1,0 ;$ compr. da caudícula $=$ $56,5 \pm 0,9$, larg. da caudícula na porção mediana $=10,9$ $\pm 0,2$, larg. da caudícula na inserção com o corpúsculo $=17,1 \pm 0,2$, larg. da caudícula na inserção com a polínia $=26,0 \pm 0,6 ;$ compr. do corpúsculo $=190,7 \pm$ 0,5 , larg. do corpúsculo $=104,8 \pm 0,5$.

M.S.F. Silvestre 62: compr. da polínia $=185,3 \pm$ 0,8 , larg. da polínia $=87,4 \pm 1,6 ;$ compr. da caudícula $=57,7 \pm 1,1$, larg. da caudícula na porção mediana $=15,2 \pm 0,4$, larg. da caudícula na inserção com o corpúsculo $=20,1 \pm 0,3$, larg. da caudícula na inserção com a polínia $=31,7 \pm 0,6$; compr. do corpúsculo $=$ $206,9 \pm 1,2$, larg. do corpúsculo $=113,6 \pm 0,8$.

Observações: no espécime J.S. Silva 289 o corpúsculo é menor que a polínia já nos espécimes L.B. Noffs 50 \& M. Goes 501 e M.S.F. Silvestre 62 são maiores. O espécime de Ditassa tomentosa descrito por Konno (2005) apresentou medidas dos corpúsculos dentro da faixa de variação dos espécimes aqui examinados, mas as medidas das polínias foram bem menores. As caudículas foram descritas por essa autora como sendo planas e de orientação horizontal enquanto que nos três espécimes da Reserva eram cilíndricas e com orientação curva. 

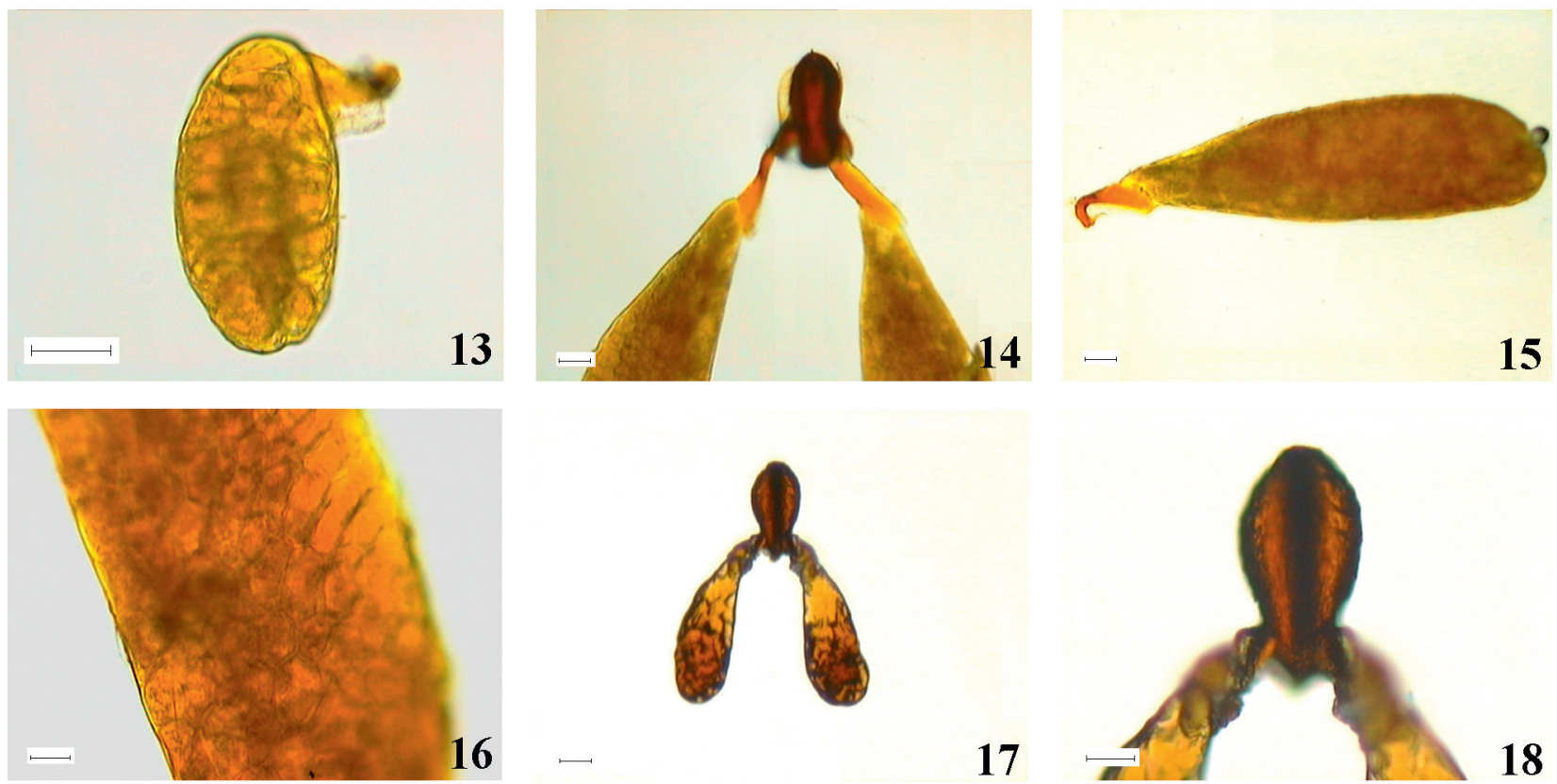

16
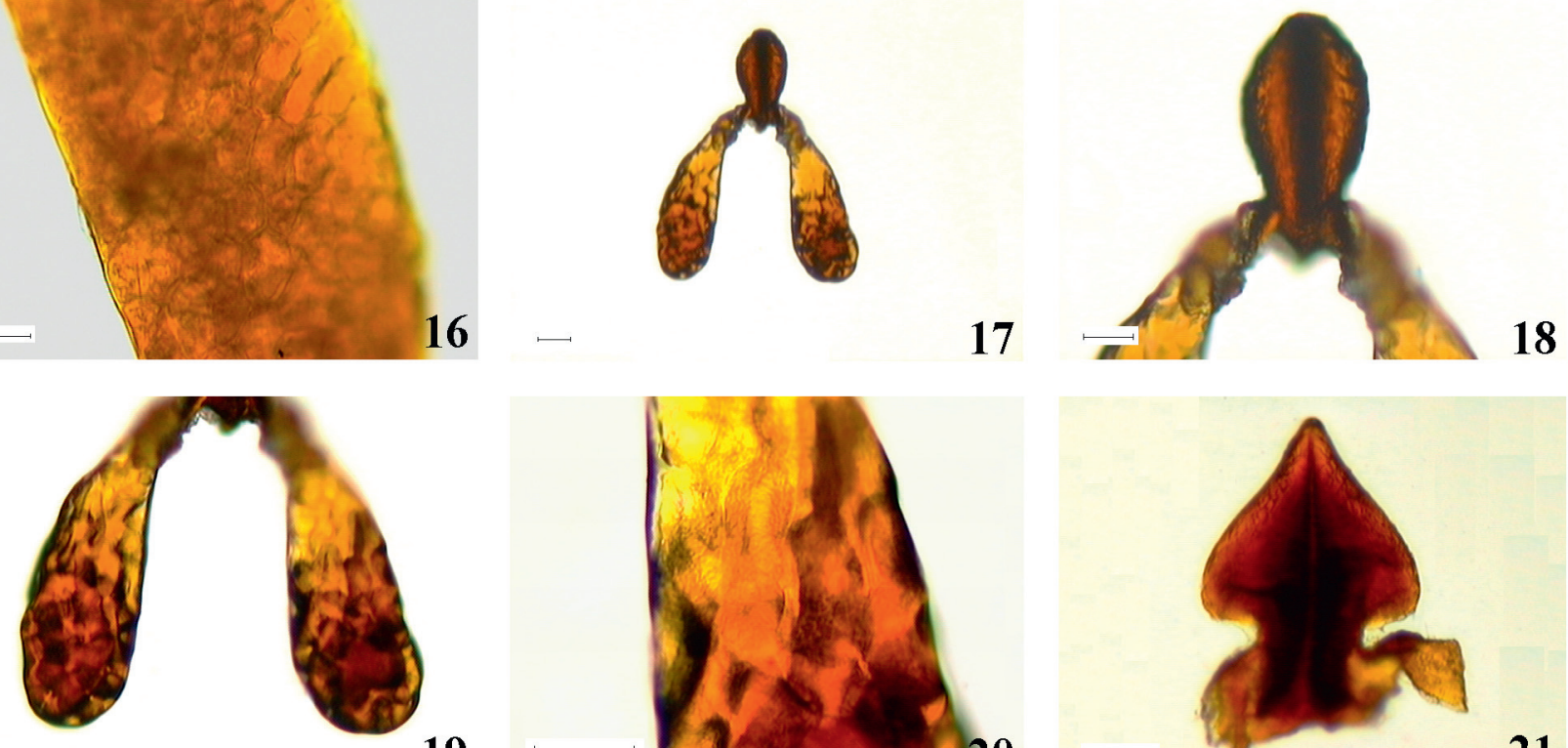

19
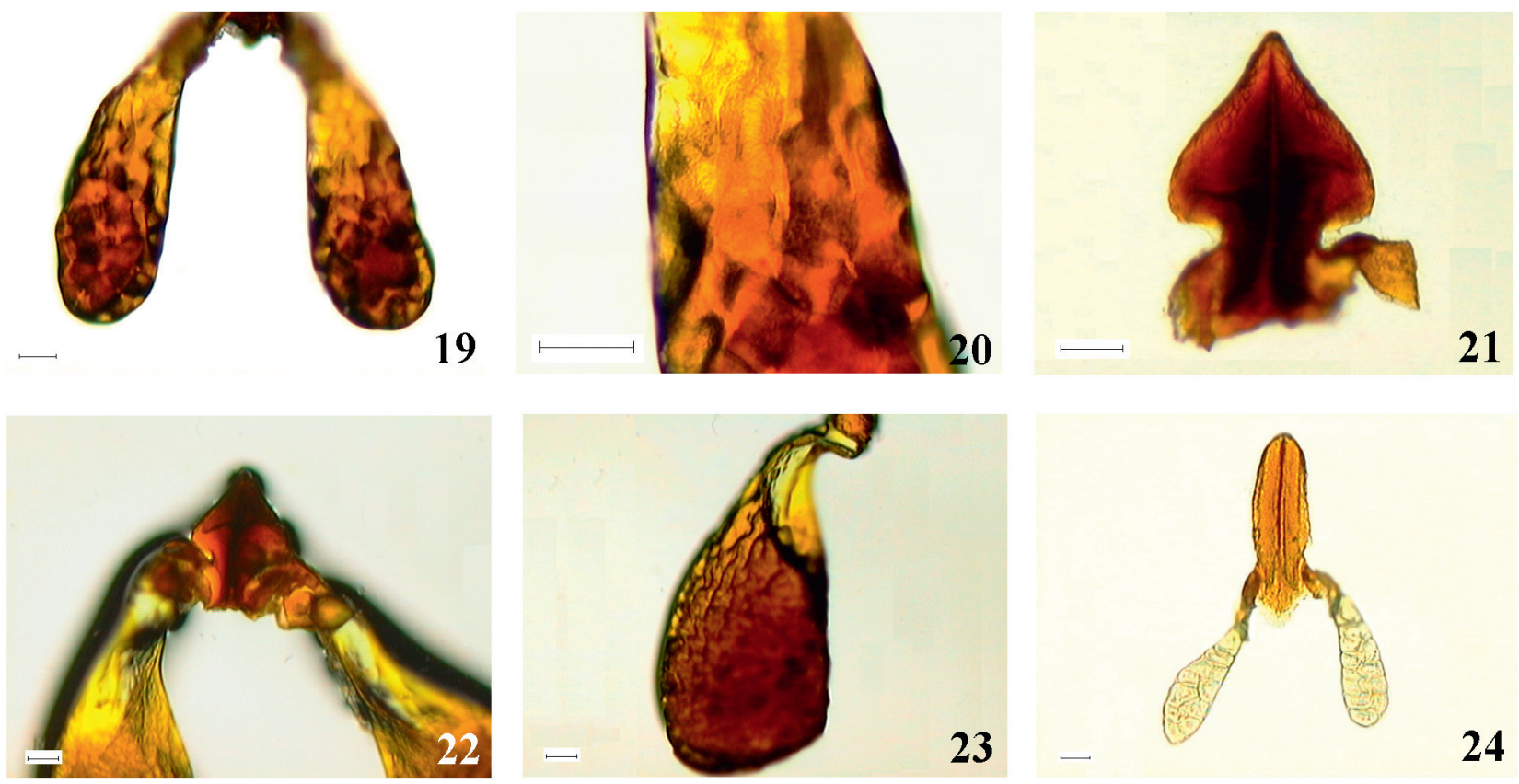

Figuras 13-24. Fotomicrografias dos polinários da família Asclepiadaceae. 13. Ditassa tomentosa (Decne.) Fontella. Polínia e caudícula, mostrando a membrana reticulada basal. 14-16. Gomphocarpus physocarpus E. Mey. 14. Vista geral do polinário. 15. Polínia e caudícula removidas do polinário. 16. Detalhe dos grãos de pólen na polínia. 17-20. Gonioanthela axillaris (Vell.) Fontella \& E.A. Schwarz. 17. Vista geral do polinário. 18. Corpúsculo e caudículas. 19. Polínias e caudículas. 20. Detalhe dos grãos de pólen na polínia. 21-23. Matelea glaziovii (E. Fourn.) Morillo. 21. Corpúsculo. 22. Corpúsculo e caudículas. 23. Polínia. 24. Orthosia urceolata Fourn. Vista geral do polinário. Escalas nas figuras 13, 16, $17=50 \mu \mathrm{m} ; 18-20,24=30 \mu \mathrm{m}$; demais figuras $=100 \mu \mathrm{m}$.

Figures 13-24. Photomicrographs of pollinaria of Asclepiadaceae. 13. Ditassa tomentosa (Decne.) Fontella. Pollinium and caudicle, showing the reticulated basal membrane. 14-16. Gomphocarpus physocarpus E. Mey. 14. General view of the pollinarium. 15. Pollinia and caudicle removed from the pollinarium. 16. Detail of the pollen grains inside the pollinium. 17-20. Gonioanthela axillaris (Vell.) Fontella \& E.A. Schwarz. 17. General view of the pollinarium. 18. Corpuscle and caudicles. 19. Pollinia and caudicle. 20. Detail of the pollen grains inside the pollinium. 21-23. Matelea glaziovii (E. Fourn.) Morillo. 21. Corpuscle. 22. Corpuscle and caudicle. 23. Pollinium. 24. Orthosia urceolata Fourn. General view of the pollinarium. Scales in the figures 13, 16, $17=50 \mu \mathrm{m} ; 18-20,24=30 \mu \mathrm{m}$; remaining figures $=100 \mu \mathrm{m}$. 
Material estudado: 30-III-1978, L.B. Noffs $50 \& M$. Goes 501 (SP); 23-IV-1974, J.S. Silva 289 (SP); 1-VI1977, M.S.F. Silvestre 62 (SP).

Chave para as espécies de Ditassa

1. Ausência de membrana reticulada basal .................... Ditassa burchellii var. vestita

1. Presença de membrana reticulada basal Ditassa hispida Ditassa tomentosa

Gomphocarpus R. Br.

1. Gomphocarpus physocarpus E. Mey.

Figuras 14-16

Polínia: clavada, de inserção terminal e orientação pendular em relação à caudícula.

Caudícula: de orientação oblíquo-descendente, retorcendo-se quando o polinário é retirado da flor, cilíndrica, inseridas na região basal do corpúsculo.

Corpúsculo: oblongo.

Relação de comprimento corpúsculo/polínia: corpúsculo muito menor do que a polínia.

Medidas $(\mu \mathrm{m})$ : compr. da polínia $=1339,8 \pm 2,8$, larg. da polínia $=380,1 \pm 3,0$; compr. da caudícula $=191,6 \pm 5,1$, larg. da caudícula na porção mediana $=51,6 \pm 1,9$, larg. da caudícula na inserção com o corpúsculo $=51,8 \pm 1,6$, larg. da caudícula na inserção com a polínia $=89,5 \pm 3,0 ;$ compr. do corpúsculo $=$ $341,6 \pm 0,7$, larg. do corpúsculo $=142,0 \pm 0,8$.

Observações: o referido espécime foi citado por Pereira (1998) como Gomphocarpus fruticosus (L.) Ait.f., entretanto, segundo Pereira (2005), o mesmo é sinônimo de Gomphocarpus physocarpus E. Mey.

Material estudado: 11-IV-1977, M.S.F. Silvestre 26 (SP).

\section{Gonioanthela Malme}

1. Gonioanthela axillaris (Vell.) Fontella \& E.A. Schwarz

Figuras 17-20

Polínia: clavada, de inserção terminal e orientação pendular em relação à caudícula.

Caudícula: de orientação oblíquo-descendente, retorcendo-se quando o polinário é retirado da flor, plana, retangular, inserida na região basal do corpúsculo.
Corpúsculo: oblongo.

Relação de comprimento corpúsculo/polínia: corpúsculo muito menor do que a polínia.

Medidas $(\mu \mathrm{m})$ : compr. da polínia $=223,9 \pm 2,1$, larg. da polínia $=91,4 \pm 1,0$; compr. da caudícula $=$ $68,9 \pm 1,7$, larg. da caudícula na porção mediana $=25,6$ $\pm 1,0$, larg. da caudícula na inserção com o corpúsculo $=20,2 \pm 0,7$, larg. da caudícula na inserção com a polínia $=28,9 \pm 1,2$; compr. do corpúsculo $=147,4 \pm$ 1,1, larg. do corpúsculo $=77,9 \pm 0,4$.

Material estudado: 27-XI-1931, F.C. Hoehne s.n. (SP28534).

\section{Matelea Aubl.}

\section{Matelea glaziovii (E. Fourn.) Morillo}

Figuras 21-23

Polínia: clavada, de inserção terminal e orientação pendular em relação à caudícula.

Caudícula: de orientação sinuosa a sigmóide, retorcendo-se quando o polinário é retirado da flor, plana, retangular, inserida na região basal do corpúsculo.

Corpúsculo: deltóide.

Relação de comprimento corpúsculo/polínia: corpúsculo muito menor do que a polínia

Medidas ( $\mu \mathrm{m}):$ F. Barros 444: compr. da polínia $=$ $1265,1 \pm 5,9$, larg. da polínia $=560,5 \pm 1,0 ;$ compr. da caudícula $=215,9 \pm 3,0$, larg. da caudícula na porção mediana $=146,6 \pm 4,5$, larg. da caudícula na inserção com o corpúsculo $=152,4 \pm 1,9$, larg. da caudícula na inserção com a polínia $=112,9 \pm 2,1$; compr. do corpúsculo $=492,0 \pm 2,2$, larg. do corpúsculo $=321,6$ $\pm 2,7$.

F.C. Hoehne s.n., SP29809: compr. da polínia $=$ $1224,0 \pm 5,2$, larg. da polínia $=547,9 \pm 3,2 ;$ compr. da caudícula $=219,1 \pm 2,1$, larg. da caudícula na porção mediana $=155,0 \pm 3,4$, larg. da caudícula na inserção com o corpúsculo $=162,6 \pm 2,2$, larg. da caudícula na inserção com a polínia $=115,1 \pm 1,6$; compr. do corpúsculo $=519,5 \pm 1,6$, larg. do corpúsculo $=307,5$ $\pm 3,2$.

M. Kirizawa 138: compr. da polínia $=1279,9 \pm$ 5,1 , larg. da polínia $=570,8 \pm 2,2 ;$ compr. da caudícula $=228,4 \pm 2,3$, larg. da caudícula na porção mediana $=145,8 \pm 3,6$, larg. da caudícula na inserção com o corpúsculo $=164,9 \pm 1,8$, larg. da caudícula na inserção com a polínia $=133,9 \pm 2,9 ;$ compr. do corpúsculo $=$ $504,6 \pm 1,9$, larg. do corpúsculo $=303,3 \pm 2,3$. 
H. Makino \& M. Kirizawa 143: compr. da polínia $=1266,9 \pm 7,0$, larg. da polínia $=532,8 \pm 3,1$; compr . da caudícula $=225,9 \pm 1,8$, larg. da caudícula na porção mediana $=179,4 \pm 2,6$, larg. da caudícula na inserção com o corpúsculo $=164,3 \pm 1,0$, larg. da caudícula na inserção com a polínia $=166,0 \pm$ 1,7 ; compr. do corpúsculo $=514,1 \pm 1,8$, larg. do corpúsculo $=275,4 \pm 1,1$.

Material estudado: 2-X-1980, F. Barros 444 (SP); 14-X-1932, F.C.Hoehne s.n.(SP29809); 29-IX-1977, M. Kirizawa 138 (SP); 26-IX-1978, H. Makino \& M. Kirizawa 143 (SP).

\section{Orthosia Decne.}

\section{Orthosia urceolata E. Fourn.}

Figuras 24-26

Polínia: clavada, de inserção terminal e orientação pendular em relação à caudícula.

Caudícula: de orientação oblíquo-descendente a curva, retorcendo-se quando o polinário é retirado da flor, cilíndrica, inserida na região basal do corpúsculo.

Corpúsculo: linear.

Relação de comprimento corpúsculo/polínia: corpúsculo maior do que a polínia.

Medidas ( $\mu \mathrm{m})$ : M. Kuhlmann 3873: compr. da polínia $=164,5 \pm 0,8$, larg. da polínia $=56,5 \pm 0,5$; compr. da caudícula $=70,7 \pm 0,9$, larg. da caudícula na porção mediana $=18,1 \pm 0,2$, larg. da caudícula na inserção com o corpúsculo $=12,4 \pm 0,4$, larg. da caudícula na inserção com a polínia $=14,5 \pm$ 0,2 ; compr. do corpúsculo $=186,8 \pm 1,0$, larg. do corpúsculo $=55,6 \pm 0,9$.

H. Makino 136: compr. da polínia $=148,3 \pm 0,8$ larg. da polínia $=49,0 \pm 0,3 ;$ compr. da caudícula $=$ $79,9 \pm 1,5$, larg. da caudícula na porção mediana $=17,7$ $\pm 0,3$, larg. da caudícula na inserção com o corpúsculo $=26,9 \pm 0,6$, larg. da caudícula na inserção com a polínia $=19,3 \pm 0,5 ;$ compr. do corpúsculo $=185,2 \pm$ 1,1, larg. do corpúsculo $=56,6 \pm 0,4$.

H. Makino \& D.A. De Grande 137: compr. da polínia $=159,2 \pm 0,9$, larg. da polínia $=45,3 \pm 0,4$; compr. da caudícula $=63,8 \pm 0,8$, larg. da caudícula na porção mediana $=16,1 \pm 0,3$, larg. da caudícula na inserção com o corpúsculo $=13,3 \pm 0,4$, larg. da caudícula na inserção com a polínia $=14,8 \pm$ 0,$3 ;$ compr. do corpúsculo $=176,5 \pm 0,8$, larg. do corpúsculo $=48,6 \pm 0,3$.
Observação: os materiais da Reserva F. Barros 850 (SP); S.A.C. Chiea 178 (SP); S.L. Jung \& M. Kirizawa 260 (SP); M. Kirizawa 208 (SP); M. Kirizawa 230 (SP); A.C. Maruffa et al. 7 (SP); M.G.L. Wanderley \& A. Custodio Filho 118 (SP), citados por Pereira (1998), não foram estudados por não apresentarem polinários em número suficiente para análise ou por estarem frutificados.

Material estudado: 11-VII-1956, M. Kuhlmann 3873 (SP); 18-VII-1978, H. Makino 136 (SP); 1-VII-1978, H. Makino \& D.A. De Grande 137 (SP).

\section{Oxypetalum R. Br.}

Polínias oblongas, reniformes ou clavadas, de inserção terminal e orientação pendular em relação as caudículas; caudículas de orientação oblíquoascendente, perpendiculares, curva ou oblíquodescendente, cilíndricas ou planas, inseridas na região basal dos corpúsculos, com ou sem membrana reticulada basal, com ou sem asas; corpúsculos lineares ou ovóides a oblongos, menores ou maiores que as polínias.

\section{Oxypetalum appendiculatum Mart.}

Figuras 27-29

Polínia: oblonga.

Caudícula: de orientação perpendicular, cilíndrica, apresenta asa, ausência de membrana reticulada basal.

Corpúsculo: linear, presença de apêndice extracorpúsculo.

Relação de comprimento corpúsculo/polínia: corpúsculo maior que a polínia.

Medidas ( $\mu \mathrm{m})$ : F.C. Hoehne s.n., SP27141: compr. da polínia $=717,1 \pm 2,6$, larg. da polínia $=$ $188,3 \pm 1,8 ;$ compr. da caudícula $=404,9 \pm 5,3$, larg. da caudícula na porção mediana $=27,6 \pm 0,4$, larg. da caudícula na inserção com o corpúsculo $=36,0 \pm 0,7$, larg. da caudícula na inserção com a polínia $=70,5 \pm$ 1,2 ; compr. da margem externa da asa $=423,6 \pm 2,8$, larg. da margem externa da asa $=36,5 \pm 1,0$; compr. do corpúsculo $=925,9 \pm 3,3$, larg. do corpúsculo $=$ $121,8 \pm 1,4$.

A.A. Bordo s.n., SP113824: compr. da polínia $=$ $667,8 \pm 1,4$, larg. da polínia $=235,0 \pm 0,9 ;$ compr. da caudícula $=388,5 \pm 3,9$, larg. da caudícula na porção mediana $=32,9 \pm 0,4$, larg. da caudícula na inserção com o corpúsculo $=29,6 \pm 0,6$, larg. da caudícula na inserção com a polínia $=94,0 \pm 1,1 ;$ compr. da margem 

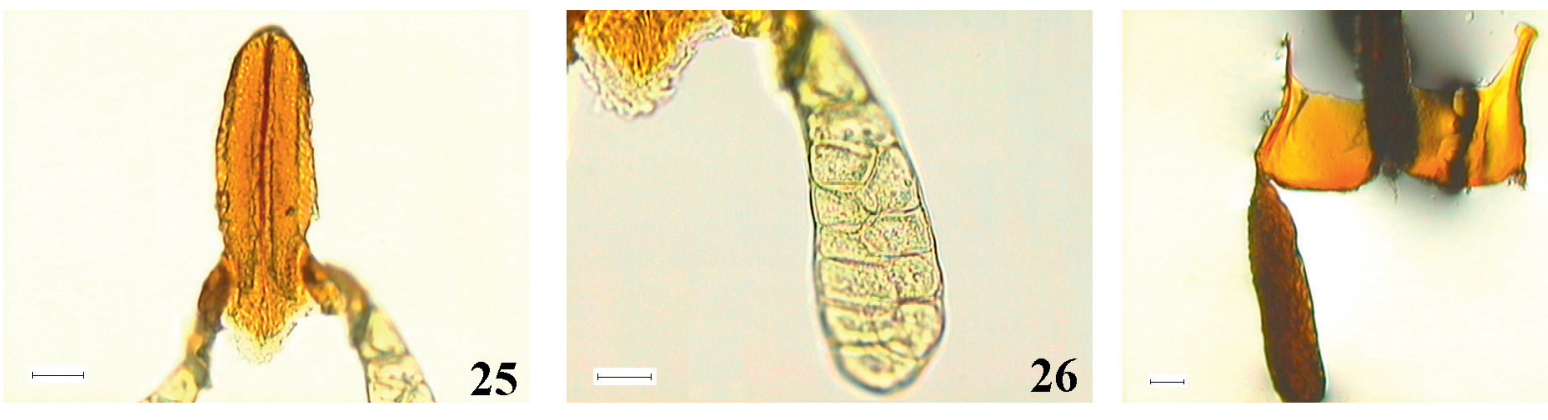

27
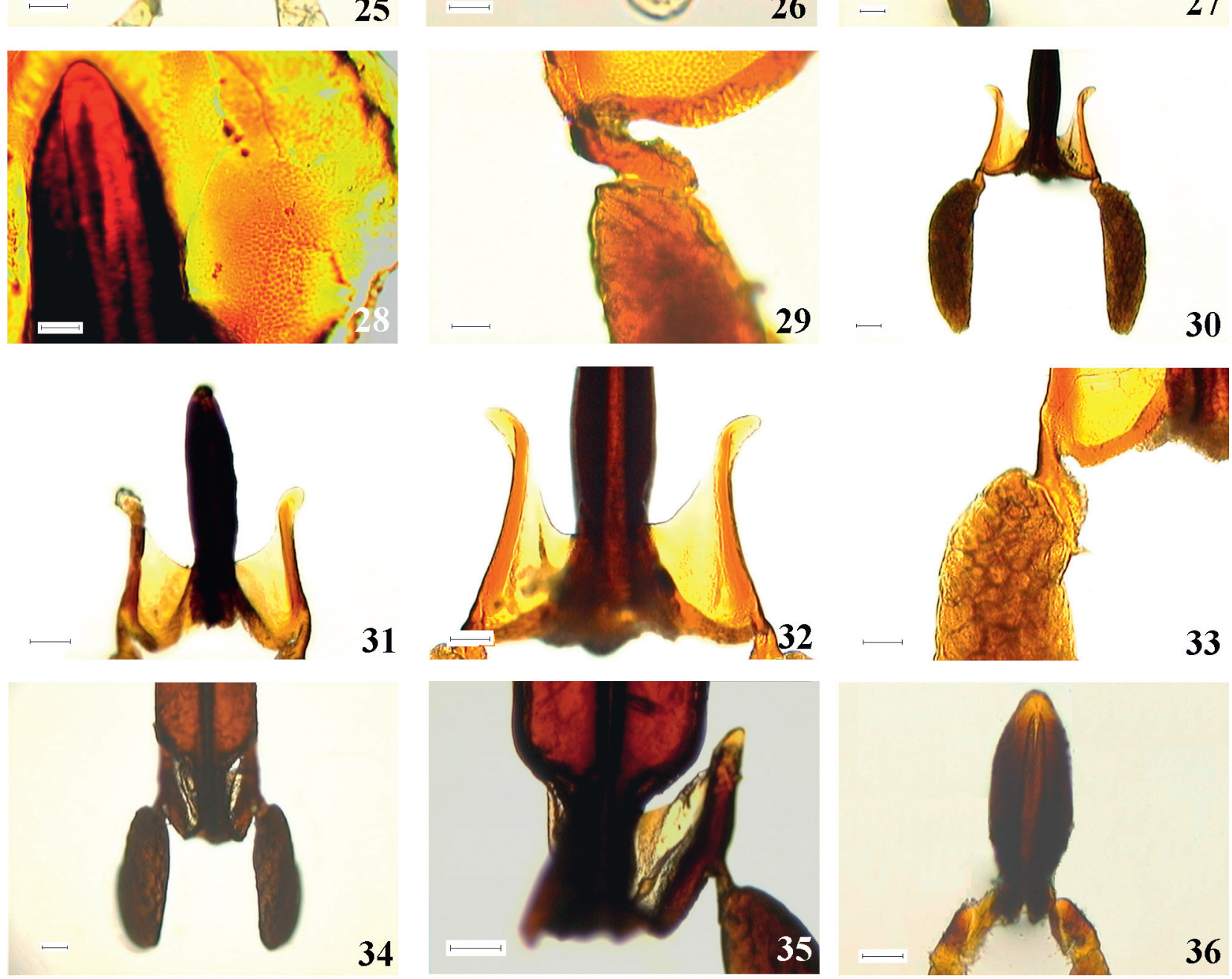

Figuras 25-36. Fotomicrografias dos polinários da família Asclepiadaceae. 25-26. Orthosia urceolata Fourn. 25. Corpúsculo. 26. Polínia. 27-29. Oxypetalum appendiculatum Mart. 27. Vista geral do polinário. 28. Detalhe do apêndice do corpúsculo. 29. Detalhe mostrando a inserção da polínia na caudícula. 30-33. Oxypetalum capitatum subsp. capitatum Mart. 30. Vista geral do polinário. 31. Corpúsculo, caudículas e asas. 32. Detalhe das asas das caudículas. 33. Detalhe mostrando a inserção da caudícula na polínia. 34-35. Oxypetalum insigne (Decne.) Malme. 34. Vista geral do polinário. 35. Detalhe da asa da caudícula. 36. Oxypetalum pachyglossum Decne. Corpúsculo. Escalas nas figuras $26=20 \mu \mathrm{m} ; 25,28,29=30 \mu \mathrm{m} ; 32,33=50 \mu \mathrm{m}$; demais figuras $=100 \mu \mathrm{m}$.

Figures 25-36. Photomicrographs of pollinaria of Asclepiadaceae. 25-26. Orthosia urceolata Fourn. 25. Corpuscle. 26. Pollinium. 2729. Oxypetalum appendiculatum Mart. 27. General view of the pollinarium. 28. Detail of the corpuscle appendage. 29. Detail showing the attachment of pollinium to caudicle. 30-33. Oxypetalum capitatum subsp. capitatum Mart. 30. General view of the pollinarium. 31 . Corpuscle and "winged" caudicles. 32. Detail of the "winged" caudicle. 33. Detail showing the attachment of pollinium to caudicle. 34-35. Oxypetalum insigne (Decne.) Malme. 34. General view of the pollinarium. 35. Detail of the "winged" caudicle. 36. Oxypetalum pachyglossum Decne. Corpuscle. Scales in the figures $26=20 \mu \mathrm{m} ; 25,28,29=30 \mu \mathrm{m} ; 32,33=50 \mu \mathrm{m}$; remaining figures $=100 \mu \mathrm{m}$. 
externa da asa $=333,5 \pm 2,8$, larg. da margem externa da asa $=41,3 \pm 1,2 ;$ compr. do corpúsculo $=955,3 \pm$ 2,0, larg. do corpúsculo $=157,1 \pm 0,9$.

T. Sendulsky 513: compr. da polínia $=696,4 \pm 3,1$, larg. da polínia $=175,1 \pm 1,1$; compr. da caudícula $=439,9 \pm 5,2$, larg. da caudícula na porção mediana $=38,4 \pm 0,9$, larg. da caudícula na inserção com o corpúsculo $=34,5 \pm 0,6$, larg. da caudícula na inserção com a polínia $=39,9 \pm 1,2 ;$ compr. da margem externa da asa $=352,6 \pm 3,2$, larg. da margem externa da asa $=$ $47,5 \pm 0,9$; compr. do corpúsculo $=982,0 \pm 3,6$, larg. do corpúsculo $=153,6 \pm 1,3$.

Observação: os espécimes da Reserva $M$. Kirizawa 192 (SP) e M.S.F. Silvestre 67 (SP), citados por Pereira (1998), não foram estudados por não apresentarem polinários em número suficiente para análise ou por estarem frutificados.

Material estudado: 10-I-1968, A.A. Bordo s.n. (SP113824); 19-II-1931, F.C.Hoehne s.n.(SP27141); 4-I-1967, T. Sendulsky 513 (SP).

\section{Oxypetalum capitatum subsp. capitatum Mart.}

Figuras 30-33

Polínia: reniforme.

Caudícula: de orientação perpendicular, cilíndrica, apresenta asa, ausência de membrana reticulada basal.

Corpúsculo: linear.

Relação de comprimento corpúsculo/polínia: corpúsculo menor que a polínia.

Medidas $(\mu \mathrm{m})$ : compr. da polínia $=682,6 \pm 3,9$, larg. da polínia $=193,3 \pm 1,8$; compr. da caudícula $=205,0 \pm 3,2$, larg. da caudícula na porção mediana $=22,8 \pm 0,5$, larg. da caudícula na inserção com o corpúsculo $=47,4 \pm 1,1$, larg. da caudícula na inserção com a polínia $=107,5 \pm 2,9$; compr. da margem externa da asa $=293,3 \pm 1,8$, larg. da margem externa da asa $=$ $33,1 \pm 0,4$; compr. do corpúsculo $=602,8 \pm 2,8$, larg . do corpúsculo $=123,9 \pm 1,4$.

Observação: o referido espécime foi citado por Pereira (1998) como Oxypetalum capitatum subsp. angustum, entretanto, segundo Farinaccio (2005), o mesmo é sinônimo de Oxypetalum capitatum subsp. capitatum.

Material estudado: 4-I-1934, F.C. Hoehne s.n. (SP32735).

\section{Oxypetalum insigne (Decne.) Malme}

Figuras 34-35
Polínia: oblonga.

Caudícula: de orientação perpendicular a oblíquoascendente, cilíndrica, apresenta asa, ausência de membrana reticulada basal.

Corpúsculo: linear.

Relação de comprimento corpúsculo/polínia: corpúsculo maior que a polínia.

Medidas ( $\mu \mathrm{m})$ : F. C. Hoehne s.n., SP38561: compr. da polínia $=502,9 \pm 1,2$, larg. da polínia $=$ $170,8 \pm 1,3$; compr. da caudícula $=182,4 \pm 2,8$, larg. da caudícula na porção mediana $=32,3 \pm 0,9$, larg. da caudícula na inserção com o corpúsculo $=32,5 \pm 1,1$, larg. da caudícula na inserção com a polínia $=54,4 \pm$ 0,9 ; compr. da margem externa da asa $=225,9 \pm 0,9$, larg. da margem externa da asa $=62,0 \pm 0,8$; compr. do corpúsculo $=1341,5 \pm 2,8$, larg. do corpúsculo $=$ $345,5 \pm 2,3$.

O. Handro 599: compr. da polínia $=502,8 \pm 1,5$, larg. da polínia $=168,8 \pm 2,1$; compr. da caudícula $=167,5 \pm 3,3$, larg. da caudícula na porção mediana $=53,4 \pm 1,0$, larg. da caudícula na inserção com o corpúsculo $=50,4 \pm 1,8$, larg. da caudícula na inserção com a polínia $=54,8 \pm 1,5$; compr. da margem externa da asa $=216,1 \pm 1,4$, larg. da margem externa da asa $=63,9 \pm 0,9 ;$ compr. do corpúsculo $=1322,0 \pm 2,8$, larg. do corpúsculo $=330,4 \pm 0,8$.

Material estudado: 7-V-1936, F.C. Hoehne s.n. (SP38561); 10-V-1936, O. Handro 599 (SP).

\section{Oxypetalum pachyglossum Decne.}

Figuras 36-38

Polínia: clavada.

Caudícula: de orientação curva, retorcendo-se quando o polinário é retirado da flor, plana, retangular, ausência de membrana reticulada basal e de asa.

Corpúsculo: ovóide a obovóide.

Relação de comprimento corpúsculo/polínia: corpúsculo menor que a polínia.

Medidas ( $\mu \mathrm{m})$ : $O$. Handro 493: compr. da polínia $=757,1 \pm 3,9$, larg. da polínia $=233,6 \pm 1,7$; compr. da caudícula $=205,3 \pm 3,4$, larg. da caudícula na porção mediana $=85,9 \pm 1,9$, larg. da caudícula na inserção com o corpúsculo $=78,6 \pm 2,2$, larg. da caudícula na inserção com a polínia $=81,1 \pm 1,3 ;$ compr. do corpúsculo $=557,3$ $\pm 3,3$, larg. do corpúsculo $=208,5 \pm 0,9$.

M.M.R.F. Melo et al. 241: compr. da polínia $=$ $611,9 \pm 3,1$, larg. da polínia $=213,8 \pm 1,9 ;$ compr. da caudícula $=264,0 \pm 2$, larg. da caudícula na porção mediana $=91,4 \pm 2,1$, larg. da caudícula na inserção com 
o corpúsculo $=88,0 \pm 1,6$, larg. da caudícula na inserção com a polínia $=91,5 \pm 1,7$; compr. do corpúsculo $=$ $519,6 \pm 1,3$, larg. do corpúsculo $=206,4 \pm 0,8$.

M.M.R.F. Melo 274: compr. da polínia $=695,3 \pm$ 3,6, larg. da polínia $=224,5 \pm 1,1$; compr. da caudícula $=223,0 \pm 4,5$, larg. da caudícula na porção mediana $=109,1 \pm 2,2$, larg. da caudícula na inserção com o corpúsculo $=72,9 \pm 1,7$, larg. da caudícula na inserção com a polínia $=86,4 \pm 1,4$; compr. do corpúsculo $=$ $587,8 \pm 2,9$, larg. do corpúsculo $=211,3 \pm 1,8$.

N.A. Rosa \& J.M. Pires 3695: compr. da polínia $=$ $710,4 \pm 1,7$, larg. da polínia $=226,4 \pm 1,6$; compr. da caudícula $=256,0 \pm 2,1$, larg. da caudícula na porção mediana $=83,9 \pm 2,6$, larg. da caudícula na inserção com o corpúsculo $=87,5 \pm 1,1$, larg. da caudícula na inserção com a polínia $=86,4 \pm 0,8 ;$ compr. do corpúsculo $=$ $583,4 \pm 3,1$, larg. do corpúsculo $=186,1 \pm 0,6$.

Material estudado: 14-I-1941, O. Handro 493 (SP); 14-XI-1980, M.M.R.F. Melo et al. 241 (SP); 25-XI1981, M.M.R.F. Melo 274 (SP); 14-XI-1980, N.A. Rosa \& J.M. Pires 3695 (SP).

\section{Oxypetalum pedicellatum Decne.}

Figuras 39-41

Polínia: oblonga.

Caudícula: de orientação perpendicular, cilíndrica, apresenta asa, ausência de membrana reticulada basal.

Corpúsculo: linear.

Relação de comprimento corpúsculo/polínia: corpúsculo maior que a polínia.

Medidas ( $\mu \mathrm{m})$ : M. Kirizawa 353: compr. da polínia $=506,8 \pm 4,1$, larg. da polínia $=124,1 \pm 1,5$; compr. da caudícula $=143,9 \pm 2,1$, larg. da caudícula na porção mediana $=15,6 \pm 0,7$, larg. da caudícula na inserção com o corpúsculo $=35,5 \pm 1,2$, larg. da caudícula na inserção com a polínia $=42,4 \pm 0,9$; compr. da margem externa da asa $=183,4 \pm 1,8$, larg. da margem externa da asa $=20,1 \pm 0,5$; compr. do corpúsculo $=839,8 \pm 5,1$, larg. do corpúsculo $=$ $177,3 \pm 0,6$.

M. Sakane 253: compr. da polínia $=510,9 \pm 0,8$, larg. da polínia $=133,0 \pm 0,9$; compr. da caudícula $=133,9 \pm 5,5$, larg. da caudícula na porção mediana $=13,4 \pm 0,5$, larg. da caudícula na inserção com o corpúsculo $=27,4 \pm 0,6$, larg. da caudícula na inserção com a polínia $=41,5 \pm 1,5$; compr. da margem externa da asa $=153,5 \pm 1,3$, larg. da margem externa da asa $=$ $16,1 \pm 0,4$; compr. do corpúsculo $=909,0 \pm 1,8$, larg . do corpúsculo $=182,1 \pm 0,8$.

Material estudado: 23-XI-1978, M. Kirizawa 353 (SP); 16-XII-1974, M. Sakane 253 (SP).

\section{Oxypetalum wightianum Hook. \& Arn.}

Figuras 42-44

Polínia: reniforme.

Caudícula: de orientação oblíquo-descendente, cilíndrica, apresenta asa, ausência de membrana reticulada basal.

Corpúsculo: linear.

Relação de comprimento corpúsculo/polínia: corpúsculo maior que a polínia.

Medidas $(\mu \mathrm{m})$ : compr. da polínia $=373,8 \pm 1,7$, larg. da polínia $=133,4 \pm 2,1$; compr. da caudícula $=$ $169,5 \pm 2,7$, larg. da caudícula na porção mediana $=22,6 \pm 0,6$, larg. da caudícula na inserção com o corpúsculo $=17,5 \pm 0,6$, larg. da caudícula na inserção com a polínia $=40,0 \pm 0,4$; compr. da margem externa da asa $=291,1 \pm 1,6$, larg. da margem externa da asa $=$ $25,0 \pm 0,8$; compr. do corpúsculo $=506,4 \pm 2,3$, larg . do corpúsculo $=132,9 \pm 1,6$.

Material estudado: 28-I-1932, F.C. Hoehne s.n. (SP29551).

Chave para as espécies de Oxypetalum

1. Presença de apêndice extra-corpúsculo

Oxypetalum appendiculatum

1. Ausência de apêndice extra-corpúsculo

2. Ausência de asas

Oxypetalum pachyglossum

2. Presença de asas

3. Polínia reniforme

4. Caudícula de orientação oblíquo-descendente Oxypetalum wightianum

4. Caudícula de orientação perpendicular

3. Polínia oblonga

5. Comprimento do corpúsculo $\geq 1.100 \mu \mathrm{m}$ Oxypetalum insigne

5. Comprimento do corpúsculo $\leq 950 \mu \mathrm{m}$ Oxypetalum pedicellatum 


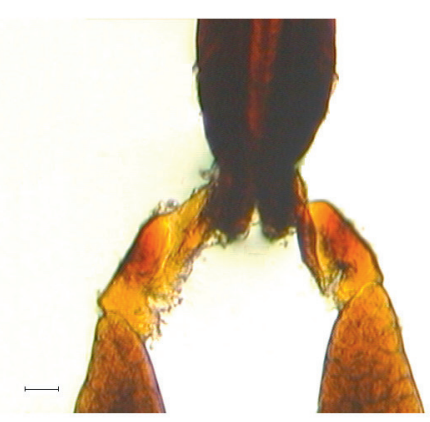

37
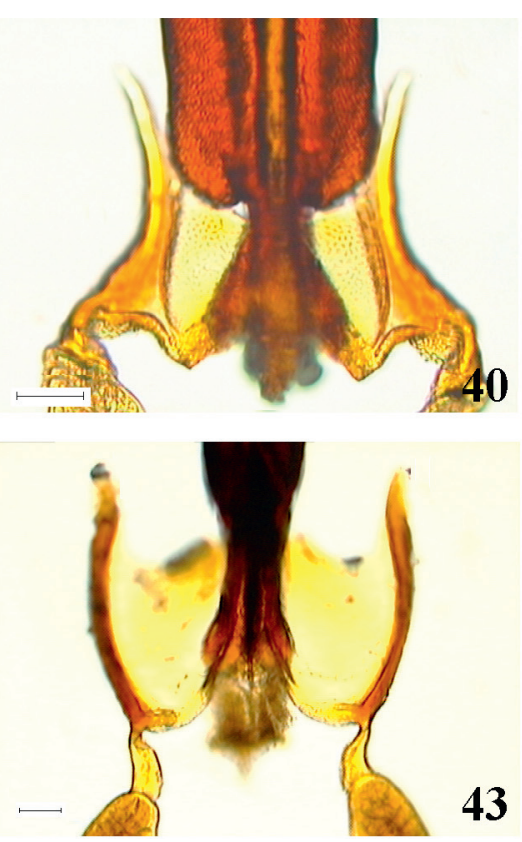

43

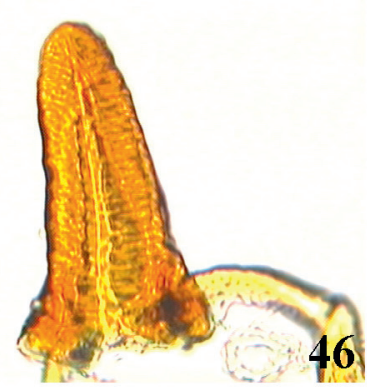

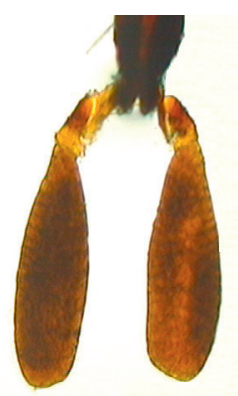

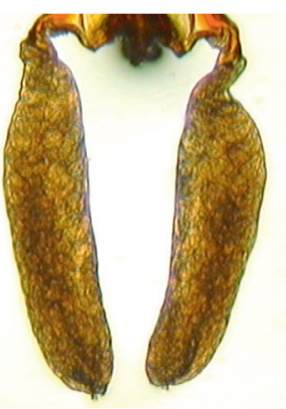

41

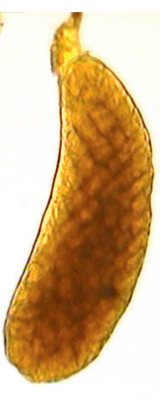

44

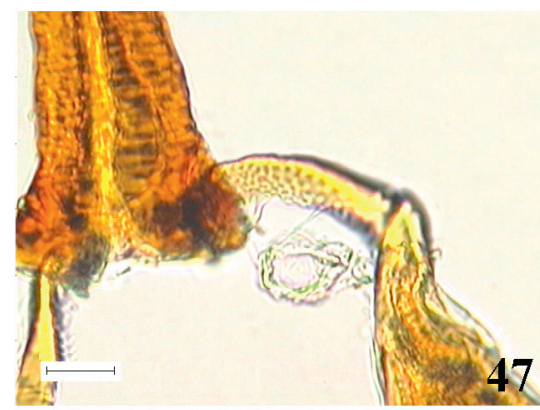

38

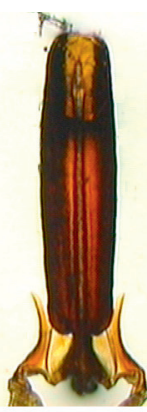

39

42
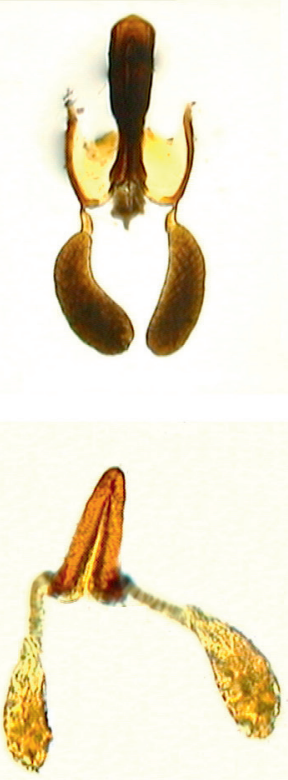

45

48

Figuras 37-48. Fotomicrografias dos polinários da família Asclepiadaceae. 37-38. Oxypetalum pachyglossum Decne. 37. Caudículas. 38. Polínias. 39-41. Oxypetalum pedicellatum Decne. 39. Corpúsculo. 40. Detalhe das asas das caudículas. 41. Polínias. 42-44. Oxypetalum wightianum Hook. \& Arn. 42. Vista geral do polinário. 43. Detalhe das asas das caudículas. 44. Polínias. 45-48. Tassadia subulata (Vell.) Fontella \& E.A. Schwarz. 45. Vista geral do polinário. 46. Corpúsculo. 47. Detalhe mostrando a inserção da caudícula na polínia. 48. Polínia. Escalas nas figuras 46, $47=20 \mu \mathrm{m} ; 48=30 \mu \mathrm{m} ; 37,40,41,43-45=50 \mu \mathrm{m} ; 38,39,42=100 \mu \mathrm{m}$.

Figures 37-48. Photomicrographs of pollinaria of Asclepiadaceae. 37-38. Oxypetalum pachyglossum Decne. 37. Caudicles. 38. Pollinia. 39-41. Oxypetalum pedicellatum Decne. 39. Corpuscle. 40. Detail of the "winged" caudicle. 41. Pollinia. 42-44. Oxypetalum wightianum Hook. \& Arn. 42. General view of the pollinarium. 43. Detail of the "winged" caudicle. 44. Pollinia. 45-48. Tassadia subulata (Vell.) Fontella \& E.A. Schwarz. 45. General view of the pollinarium. 46. Corpuscle. 47. Detail showing the attachment of pollinium to caudicle. 48. Pollinium. Scales in the figures 46, $47=20 \mu \mathrm{m} ; 48=30 \mu \mathrm{m} ; 37,40,41,43-45=50 \mu \mathrm{m} ; 38,39,42=100 \mu \mathrm{m}$. 


\section{Tassadia Decne.}

1. Tassadia subulata var. subulata (Vell.) Fontella \& E.A. Schwarz

Figuras 45-48

Polínia: clavada, de inserção terminal e orientação pendular em relação a caudícula.

Caudícula: de orientação curva, cilíndrica, inserida na região basal do corpúsculo.

Corpúsculo: deltóide.

Relação de comprimento corpúsculo/polínia: corpúsculo menor do que a polínia.

Medidas $(\mu \mathrm{m})$ : compr. da polínia $=146,1 \pm 0,5$, larg. da polínia $=58,7 \pm 0,4$; compr. da caudícula $=$ $70,7 \pm 1,0$, larg. da caudícula na porção mediana $=15,8$ $\pm 0,2$, larg. da caudícula na inserção com o corpúsculo $=15,8 \pm 0,5$, larg. da caudícula na inserção com a polínia $=19,9 \pm 0,3 ;$ compr. do corpúsculo $=134,9 \pm$ 0,5 , larg. do corpúsculo $=79,7 \pm 0,4$.

Observações: Tassadia subulata var. subulata foi descrita por Melhem et al. (2003) como possuindo polínia oblonga e de comprimento menor do que o espécime aqui examinado. O material da Reserva $O$. Handro s.n. (SP47125) citado em Pereira (1998) não foi estudado por não apresentar polinários em número suficiente para análise.

Material estudado: BRASIL. São Paulo: Universidade de São Paulo, 6-VI-1944, W. Hoehne s.n. (SP312387).

\section{Agradecimentos}

As autoras agradecem ao Programa Institucional de Bolsas de Iniciação Científica - PIBIC - CNPq, pelo auxílio financeiro concedido a Fernanda Jacinto Albanese.

\section{Literatura citada}

Cronquist, A. 1968. The evolution and classification of flowering plants. Thomas Nelson, London.

Cruz-Barros, M.A.V.\& Souza, L.N. 2005. Flora polínica da Reserva do Parque Estadual das Fontes do Ipiranga (São Paulo, Brasil). Família: 10-Piperaceae. Hoehnea 32: 77-85.

El-Gazzar, A. \& Hamza, M.K. 1973. Morphology of the twin pollinia of Asclepiadaceae. Pollen et Spores 15: 459-470.

El-Gazzar, A., Hamza, M.K. \& Badawi,A.A. 1974.Pollen morphology and taxonomy of Asclepiadaceae. Pollen et Spores 16: 227-238.
Endress,M.E.\& Bruyns, P.V.2000.A revised classification of Apocynaceae s.l. Botanical Review 66: 1-56.

Endress, M.E. \& Stevens, W.D. 2001. The renaissance of the Apocynaceae s.l.: Recent advances in systematics, phylogeny and evolution. Annals of the Missouri Botanical Garden 88: 517-522.

Farinaccio, M.A. 2005. 22. Oxypetalum R. Br. In: J.F. Pereira (coord.). Asclepiadaceae. In: M.G.L. Wanderley, G.J. Shepherd, T.S. Melhem, S.E. Martins, M. Kirizawa \& A.M. Giulietti (eds.). Flora Fanerogâmica do Estado de São Paulo. FAPESP, RiMa, São Paulo, v. 4, pp. 130-150.

Ikuse, M. 1956. Pollen grains of Japan. Hirokawa Publishing Company, Tokyo.

Konno, T.U.P. 2005. Ditassa R. Br. (ApocynaceaeAsclepiadoideae) no Brasil. Tese de Doutorado, Universidade de São Paulo, São Paulo.

Melhem, T.S., Giulietti, A.M., Forero, E., Barroso, G.M., Silvestre, M.S.F., Jung, S.L., Makino, H., Melo, M.M.R.F., Chiea, S.C., Wanderley, M.G.L., Kirizawa, M. \& Muniz, C. 1981. Planejamento para elaboração da "Flora Fanerogâmica da Reserva do Parque Estadual das Fontes do Ipiranga (São Paulo, Brasil)". Hoehnea 9: 63-74.

Melhem, T.S., Makino, H., Silvestre, M.S.F., Cruz, M.A.V. \& Jung-Mendaçolli, S. 1984. Planejamento para elaboração da "Flora Polínica da Reserva do Parque Estadual das Fontes do Ipiranga (São Paulo, Brasil)". Hoehnea 11: 1-7.

Melhem, T.S., Cruz-Barros, M.A.V., Corrêa, A.M.S., Makino-Watanabe, H., Silvestre-Capelato, M.S.F. \& Esteves, V.L.G. 2003. Variabilidade polínica em plantas de Campos do Jordão (São Paulo, Brasil). Boletim do Instituto de Botânica 16: 1-95.

Nakajima, J.N., Esteves, R.L., Gonçalves-Esteves, V., Magenta, M.A.G., Bianchini, R.S., Pruski, J.F. \& Hind, D.J.N. 2001. Flora Fanerogâmica da Reserva do Parque Estadual das Fontes do Ipiranga (São Paulo, Brasil). 159-Asteraceae. Hoehnea 28: 111-181.

Newton, L.E. 1984. Terminology of structures associated with pollinia of the Asclepiadaceae. Taxon 33: 619621.

Pereira, J.F. 1998. Flora fanerogâmica da Reserva do Parque Estadual das Fontes do Ipiranga (São Paulo, Brasil). 135-Asclepiadaceae. Hoehnea 25: 71-86.

Pereira, F.C. 2005. 9. Gomphocarpus R. Br. In: J.F. Pereira (coord.). Asclepiadaceae. In: M.G.L. Wanderley, G.J. Shepherd, T.S. Melhem, S.E. Martins, M. Kirizawa \& A.M. Giulietti, (eds.). Flora Fanerogâmica do Estado de São Paulo. FAPESP, RiMa, São Paulo, v. 4, pp. 112.

Verhoeven, R.L. \& Venter, H.J.T. 2001. Pollen morphology of the Periplocoideae, Secamonoideae and Asclepiadoideae (Apocynaceae). Annals of the Missouri Botanical Garden 88: 569-582. 